\title{
RESEARCH
}

Open Access

\section{Analysis of long-term oncological results of clinical versus pathological responses after neoadjuvant treatment in locally advanced rectal cancer}

Mariana F. Coraglio ${ }^{1 *}$ D , Martin A. Eleta ${ }^{2}$, Mirta R. Kujaruk³, Javier H. Oviedo ${ }^{4}$, Enrique L. Roca ${ }^{5}$, Guillermo A. Masciangioli ${ }^{1}$, Guillermo Mendez ${ }^{5}$ and IIma S. Iseas ${ }^{5}$

\begin{abstract}
Background: Nonoperative management after neoadjuvant treatment in low rectal cancer enables organ preservation and avoids surgical morbidity. Our aim is to compare oncological outcomes in patients with clinical complete response in watch and wait strategy with those who received neoadjuvant therapy followed by surgery with a pathological complete response.

Methods: Patients with non-metastatic rectal cancer after neoadjuvant treatment with clinical complete response in watch and wait approach (group 1, $n=26$ ) and complete pathological responders (ypTONO) after chemoradiotherapy and surgery (group 2, n=22), between January 2011 and October 2018, were included retrospectively, and all of them evaluated and followed in a multidisciplinary team. A comparative analysis of local and distant recurrence rates and disease-free and overall survival between both groups was carried out. Statistical analysis was performed using log-rank test, Cox proportional hazards regression model, and Kaplan-Meier curves.

Results: No differences were found between patient's demographic characteristics in both groups. Group 1: distance from the anal verge mean $5 \mathrm{~cm}(r=1-12), 10$ (38\%) stage III, and 7 (27\%) circumferential resection margin involved. The median follow-up of 47 months ( $r=6$, a 108). Group 2: distance from the anal verge mean $7 \mathrm{~cm}(r=2-12), 16(72 \%)$ stage III, and 13 (59\%) circumferential resection margin involved. The median follow-up 49.5 months ( $r=3$, a 112). Local recurrence: 2 patients in group $1(8.3 \%)$ and 1 in group $2(4.8 \%)(p=0.6235)$. Distant recurrence: 1 patient in group $1(3.8 \%)$ and 3 in group $2(19.2 \%)(p=0.2237)$. Disease-free survival: $87.9 \%$ in group $1,80 \%$ in group $2(p=0.7546)$. Overall survival: $86 \%$ in group 1 and 85\% in group 2 ( $p=0.5367)$.

Conclusion: Oncological results in operated patients with pathological complete response were similar to those in patients under a watch and wait strategy mediating a systematic and personalized evaluation. Surgery can safely be deferred in clinical complete responders.
\end{abstract}

Keywords: Rectal cancer, Clinical complete response, Pathological complete response, Neoadjuvant treatment, Watch and wait

\footnotetext{
* Correspondence: mcoraglio@hotmail.com

'Colorectal Surgery Unit, Gastroenterology Hospital, Dr. Carlos Bonorino

Udaondo, Av. Caseros 2061, 1264 Ciudad Autónoma de Buenos Aires (CABA), Argentina

Full list of author information is available at the end of the article
}

(c) The Author(s). 2020 Open Access This article is licensed under a Creative Commons Attribution 4.0 International License, which permits use, sharing, adaptation, distribution and reproduction in any medium or format, as long as you give appropriate credit to the original author(s) and the source, provide a link to the Creative Commons licence, and indicate if changes were made. The images or other third party material in this article are included in the article's Creative Commons licence, unless indicated otherwise in a credit line to the material. If material is not included in the article's Creative Commons licence and your intended use is not permitted by statutory regulation or exceeds the permitted use, you will need to obtain permission directly from the copyright holder. To view a copy of this licence, visit http://creativecommons.org/licenses/by/4.0/ The Creative Commons Public Domain Dedication waiver (http://creativecommons.org/publicdomain/zero/1.0/) applies to the data made available in this article, unless otherwise stated in a credit line to the data. 


\section{Introduction}

Total mesorectal excision (TME) surgery has been the historical standard of care for the cure of rectal cancer. Neoadjuvant chemoradiotherapy (CRTn) was incorporated a few decades ago as an additional and valuable tool to treat locally advanced tumors. This therapy can achive a better local control of the disease [1,2] and clinical or pathological complete response. Habr-Gama et al. [3] and other groups of researchers described acceptable long-term oncological results with a nonoperative management called watch and wait (WW) in patients with clinical complete response (cCR), similar to those observed in patients with pathological complete response (pCR) after surgical resection. Several international series reflect variable rates of complete response, ranging from 2 to $78.4 \%$ of $\mathrm{cCr}$ and from 6.5 to $30 \%$ of pCR [4-12]. Furthermore, the complete response after CRTn represents a surrogate endpoint for improved overall survival $[4,10,13]$.

One of the controversial issues of this pathological entity is sphincter preservation, which is still impossible in up to $50 \%$ of low rectum tumor cases, causing a negative impact on the physical and emotional sphere as well as on the quality of life of patients and even their families $[1,3,6]$.

The WW strategy is increasingly accepted as it allows organ preservation and avoids surgical morbidity and mortality; however, despite the large number of publications, it is under constant evaluation and continues to be considered a controversial topic [9, 14-17].
The aim of this study is to evaluate whether the oncological results after CRTn followed by surgery in patients with rectal cancer and pCR are better than those in patients with clinical complete response under a non-operative strategy.

\section{Materials and methods}

Between January 2011 and October 2018, 256 patients with rectal adenocarcinoma who underwent CRTn were consecutively registered in a prospective database (58.71\% of the patients with rectal cancer who were evaluated for treatment), 26 of whom achieved $\mathrm{CCR}$ and remained under the WW strategy and 130 underwent TME, 22 of whom achieved pCR (Fig. 1).

Inclusion criteria for our study were as follows:

1. Diagnosis of adenocarcinoma of the rectum located up to $12 \mathrm{~cm}$ from the anal verge in proctological exam presenting clinical complete response after CRTn who remains in the WW approach or pathological complete response after CRTn and surgery.

2. Initial clinical staging with magnetic resonance imaging (MRI) complying with high resolution parameters (3-mm slice thickness, 16-20 cm FOV, a matrix of $256 \times 256$ minimum [18])

3. Chest computed tomography scan (CT) without contrast

4. Analyzed in "Co-recto," that is our multidisciplinary team.

ocally Advance Rectal cancer in

database

$\mathrm{n}: 436$

- Digital rectal examination up to $12 \mathrm{~cm}$

- Abdomen and pelvic MRI

- Thorax CT

- Discussed in multidisciplinary team

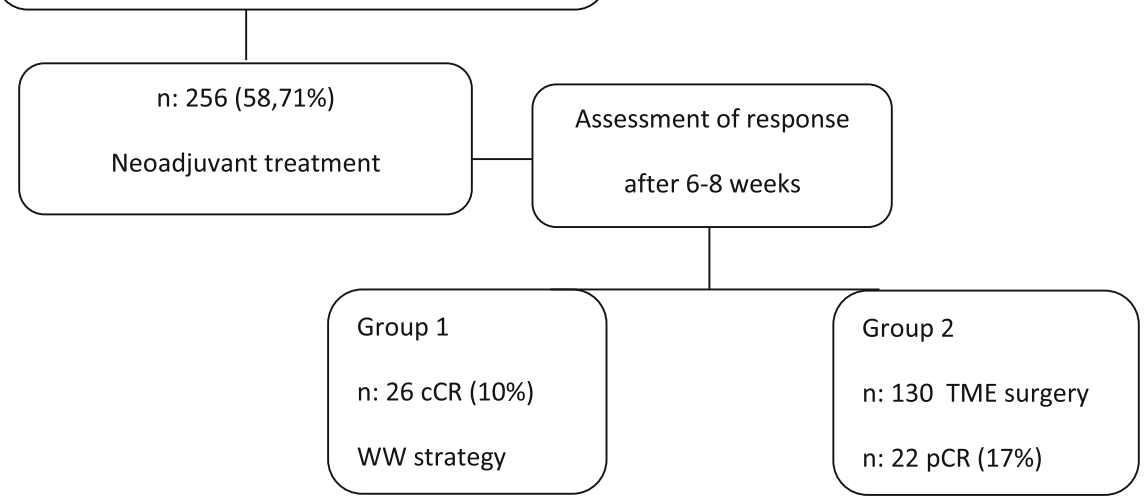

Fig. 1 Selection of patients 
Patients with a distant metastatic disease (stage IV) at initial staging or at the end of the treatment were excluded.

The absence of clinically detectable residual tumor by proctologic and endoscopic examination was defined cCR, a flat white scar, small telangiectasias, no ulcer, no nodularity, and on imaging with MRI ymrT0 ymrNo. The absence of viable tumor cells after the complete histopathological examination of the resected surgical specimen was informed pCR (ypT0 ypN0). The WW approach is a non-operative modality for clinical complete responders to $\mathrm{nQRT}$, with a systematic follow-up.

We decided WW strategy in patients with clinical complete response when a sphincter preservation surgery is not possible or the patient does not want to be operated under any circumstances.

Two groups were formed: group 1 (G1) included the 26 patients who remained under the WW strategy and group 2 (G2) included the 22 patients who underwent TME surgery, whose pathological report was pCR (ypT0N0).

At baseline, each patient must undergo a digital rectal examination and rigid proctosigmoidoscopy, abdominal MRI, high-resolution pelvic T2W MRI (including diffusion-weighted), and thorax TC scan. Selected cases required a positron emission tomography (FDG PET/CT) procedure. The colon was examined by videocolonoscopy (VCC), and in those cases where it was incomplete, a double contrast barium enema was performed.

The therapeutic management was decided at the weekly meetings of the multidisciplinary team ("Co-recto"). The implemented neoadjuvant treatment was chemotherapy with capecitabine at a daily dose of $825 \mathrm{mg} / \mathrm{m}^{2}$ every $12 \mathrm{~h}$ continuously every weekday and concurrent $3 \mathrm{D}$ pelvic radiation therapy ranging between 4500 and 5040 cGy (depending on the treating center). Induction chemotherapy was indicated with three cycles of XELOX in patients with initial risk factors in the MRI, such as extramural vascular invasion (EMVI+), suspicious lateral lymph nodes, or highly symptomatic. Adjuvant chemotherapy was implemented in patients who presented mesorectal and/or lateral lymph node disease at initial staging.

Assessment of tumor response was performed 6 or 8 weeks after completion CRTn with the same studies done at the beginning .

A minimum waiting time of 8 weeks post CRTn was established for those patients who underwent surgery either because they presented a residual lesion or could undergo sphincter preservation surgery. TME technique was performed. In very low rectal tumors, the procedure of choice was intersphincteric resection with transanal handswen anastomoses, whereas an abdominoperineal amputation was the option in other cases. The anastomotic sites within $6 \mathrm{~cm}$ or less from the anal verge were protected with a loop ileostomy.

The anatomopathological study of the surgical resection specimens was performed by following a standardized protocol of the Hospital Pathology Service. Macroscopically, the ulcer and/or fibrosis area was sectioned at $5 \mathrm{~mm}$ intervals and total embedded. To determine the presence of residual tumor, each block was examined with a single section level stained with hematoxylin-eosin. The degree of response to the preoperative therapy was assigned in accordance to the recommendations of the College of American Pathologists (CAP) [19]. The cases presenting absence of tumor cells were registered as ypT0 and ypN0 (Grade 0 Complete response). For the classification of the pathological stage, the 8th edition UICC TNM Edition Staging System was used [20, 21].

Follow-up of the patients under WW strategy included proctologic examination, abdomen and pelvic MRI, and carcinoembryonic antigen (CEA) at 3-month intervals during the first year, annual VCC, and thorax-abdomenpelvis TC scan every 6 months; MRI for the second year every 4 months; and every 6 months for the 3rd year, continuing annually. After surgery, all patients were monitored at 3-month intervals with CEA, at least two complete CT; the first 3 years and VCC the first year, continuing according to the findings [3, 22-24].

\section{Statistical analysis}

The recurrence rate or local regrowth, distant progression, and disease-free and overall survival were evaluated in each group to determine if there were long-term differences between the two strategies analyzed.

Follow-up time was determined from the moment when WW was decided in G1 patients and from the date of surgery in G2 group, in both groups after treatment was concluded and the complete response was confirmed.

The study design was retrospective and descriptive. Statistical significance was assessed using the log-rank test for local and distant recurrence and the Cox proportional hazards regression model for overall survival. Kaplan-Meir curves were used to evaluate survival. A $p$ value less than 0.05 was considered statistically significant. The statistical analysis was performed using Medcalc 11.2.1.0 software.

\section{Results}

Twenty six patients in non-operative management (G1) and 22 patients who underwent TME and pCR (G2) were included, a total of 48 patients with complete response to the neoadjuvant treatment (27\%). The cCR rate was $10 \%$ in 256 patients who received CRTn and $17 \%$ in the 130 patients that received CRTn followed by surgery and achieved pCR. The demographic and clinical characteristics and the initial staging of both groups are described in Table 1.

Group 1: The decision to opt for non-operative management was motivated in 22 cases $(65 \%)$ by the impossibility of preserving the annal sphincter and in 4 cases 
(15\%) by the patient's decision even with the possibility of preservation. Assessment of response between the 6th and 12th week after CRTn was done in 17 patients $(65 \%)$, the remaining 9 patients (35\%) after 12 weeks. The median follow-up time was 47 months, ranging from 6 to 108 months. In three patients (11.53\%), an almost complete response was initially observed; for this reason, a fullthickness conventional transanal local excision of the rectum wall over the scar area was performed, finding only fibrosis in the histopathological study and the patients continued in WW. Two patients (8.3\%) experienced regrowth of the tumor, both on the luminal surface. One of them presented an ulcerated lesion on the tumor scar after 9 months of follow-up. A biopsy of the lesion was performed due to a high suspicion of malignancy and histologically confirmed. In another case, an irregular indurated lesion that was detected on the scar was completely resected after 10 months of follow-up, which was confirmed as pT2 pNx by histopathology. An abdominoperineal resection was performed as salvage surgery in both patients and are currently disease-free at 56 and 32 months respectively of postoperative follow-up. These were the only two cases that required salvage surgery. One patient (3.8\%) experienced distant progression, after 4 months in non-operative strategy and has been on systemic chemotherapy for 31 months, maintaining $\mathrm{cCR}$ of the primary tumor since the end of radiotherapy. At the time of this analysis, 24 patients are alive; there were two no-related cancer death.

Group 2: the response assessment between the 6th and 12th week post CRTn (range 4-12 weeks) was done in 14 patients (63.63\%). Median interval time since the end of radiotherapy to surgery was 15 weeks (range: 9-
34 weeks). The surgeries performed were anterior resection in 19 cases (86\%), intersphincteric in two (9\%), and abdominoperineal resection in one (5\%). Median follow-up time was 49.5 months, with a range of 3 to 112 months. During follow-up, local recurrence was observed in one of the 22 patients (4.8\%), 12 months after intersphincteric resection, affecting sectors of the perineum and inguinal areas, not amenable to salvage surgery. The patient died after 15 months of follow-up. Distant recurrence was observed in three patients (19.2\%). One of them presented pulmonary and hepatic metastases after 36 months of follow-up and two other patients exhibited lung metastases at 6 and 26 months after surgery. Two of the three patients died of the disease. At the time of the analysis, 19 patients are still alive.

The comparative analysis between both groups with regard to the oncological results confirmed that there are no statistically significant differences in the local or distant control in both strategies (Table 2). Local recurrence was observed in two patients in G1 (8.3\%) and in one patient in G2 (4.8\%), $(p=0.6235$, HR: $1.8004,95 \%$ IC 0.1867 to 17.3630) (Fig. 2), distant recurrence was observed in one patient in G1 (3.8\%), and in three cases in G2 (19.2\%). ( $p$ $=0.2237$, HR: $0.2700,95 \%$ IC 0.03763 to 1.9381 ) (Fig. 3). Disease-free survival was $87.9 \%$ in G1 and $80 \%$ in G2 $(p=$ 0.7546, HR: $0.8213,95 \%$ CI 0.2363 to 2.8541 ) (Fig. 4). Overall survival was $86 \%$ in G1, and $85 \%$ in G2 ( $p=$ 0.5367, HR: 0.5737, 95\% CI 0.09890 to 3.3280) (Fig. 5). Initial staging data for patients with local or distant progression in both groups are presented in Table 3.

\section{Discussion}

The option of organ preservation by implementing a WW strategy in cCR after neoadjuvant therapy has

Table 1 Demographic and pretreatment clinical characteristics

\begin{tabular}{|c|c|c|c|}
\hline & Group 1 & Group 2 & $p$ \\
\hline & cCR & $\mathrm{pCR}$ & \\
\hline n patients (\%) & $26(54.2)$ & $22(45.8)$ & \\
\hline Gender (M/F) & $13 / 13$ & $8 / 14$ & \\
\hline Age (years), median (range) & $59(32-82)$ & $55(26-73)$ & 0.2975 \\
\hline Distance from anal verge $(\mathrm{cm})$, mean (range) & $5(1-12)$ & $7(2-12)$ & 0.32 \\
\hline $\mathrm{T} 1-2, n(\%)$ & $8(31)$ & $4(18)$ & 0.5035 \\
\hline T3-4, n (\%) & $18(69)$ & $18(82)$ & 0.5035 \\
\hline cStage III (N+), n (\%) & $10(38)$ & $16(72)$ & 0.04 \\
\hline CRM+, $n(\%)$ & $7(27)$ & $13(59)$ & 0.0515 \\
\hline $\mathrm{EMVI}+, n(\%)$ & $4(15)$ & $11(50)$ & 0.0235 \\
\hline LPLN+, $n(\%)$ & $5(19)$ & $3(14)$ & 0.8969 \\
\hline CEA, $>5 \mathrm{ng} / \mathrm{dl}, n(\%)$ & $3(11)$ & $4(18)$ & 0.8108 \\
\hline Induction XELOX 3 courses, $n$ (\%) & $6(23)$ & $5(23)$ & 0.7521 \\
\hline Median follow-up-months (range) & $47(6-94)$ & $49.5(3-112)$ & 0.7848 \\
\hline
\end{tabular}

$c C R$ clinical complete response, $p C R$ pathological complete response, $F$ female, $M$ male, $N+$ lymph nodes suspected of malignancy, $C R M+$ circumferential resection margin involved, EMVI + extramural vascular invasion, LPLN lateral pelvic lymph nodes, CEA carcinoembryonic antigen, NS not significant 
Table 2 Oncological outcomes. Statistic analysis

\begin{tabular}{llll}
\hline & $\begin{array}{l}\text { Group 1 } \\
\text { CCR }\end{array}$ & $\begin{array}{l}\text { Group 2 } \\
\text { pCR }\end{array}$ & $\begin{array}{l}\boldsymbol{p} \\
\text { value }\end{array}$ \\
\hline$n$ patients & 26 & 22 & \\
Local relapse/regrowth $(n / \%)$ & $2 / 8.3 \%$ & $1 / 4.8 \%$ & 0.6235 \\
Distant recurrence $(n / \%)$ & $1 / 3.8 \%$ & $3 / 19.2 \%$ & 0.2237 \\
Disease free survival (\%) & $87.9 \%$ & $80 \%$ & 0.7546 \\
Overall survival (\%) & $86 \%$ & $85 \%$ & 0.5367 \\
\hline CCR clinical complete response, $p C R$ pathological complete response
\end{tabular}

increasingly become an attractive approach after being observed in several studies in high-volume centers that it has similar oncological results as surgery with pCR $[3,5,16]$. Functional results are added to the benefits of this strategy in avoiding morbidity and mortality resulting from surgery, as we have found in a study conducted by our team that is currently in press, in which we observed an improved the quality of life and reduced incontinence in WW patients.

Although WW has been evaluated as being viable and safe, the determination of response continues to be one of the major debate topics, as well as the eligibility criteria of the patients who could opt for this option, and the feasibility of a systematized follow-up that could allow access to the patients to a salvage surgery in the case of a change in their clinical condition $[9,22,23$, 25-31]. Because not always it is possible to detect the clinical complete responders some patients need to be operated and showed a complete pathological response (ypT0N0) like our patients in G2. Additionally in a small number of them, the surgery was performed in spite of suspected and probable clinical complete response because they could undergo to sphincter preservation surgery.
Initially in our multidisciplinary committee called "Corecto," we have cooperatively reviewed results in complete responders patients, with other centers in the Autonomous City of Buenos Aires, in which we observed that the oncological results are good and similar in patients with $\mathrm{cCR}$ and WW and with pCR. In this work, patients from a single institution have currently been evaluated [23, 32].

One of the factors that we consider of great relevance to determine the response to the treatment is to establish the best time to perform re-assessment; diverse studies have proposed from 3 to 24 weeks after the end of radiation therapy, which reflects the lack of strict consensus in this regard [3, 6, 22, 29], performing digital rectal examination, rigid proctosigmoideoscopy, abdominal and pelvic MRI, and chest CT scan. In our team, we preferred to conduct the evaluation of response at least 6 weeks after the end of neoadjuvant therapy, and in those cases with a very good response, we continued with periodic monthly reevaluations, thus postponing surgery. We decided to wait longer, thinking of the possibility of an intentional WW strategy, especially in the most distal tumors. In two of our patients, who were on an abdominoperineal resection plan, and had to wait for more than 12 weeks, the treatment had only shown a scar lesion. Hence, the indication for surgery was changed to a non-operative management. Moreover, MRI also showed CCR, and the morbidity and mortality of surgery were avoided, providing the additional benefit of sphincter preservation, without definitive stoma.

We did not perform an endoscopic biopsy of the residual lesion as a detection or confirmation tool for complete responders because, in general, the tumor involvement of the mucosa and the submucosa is modified

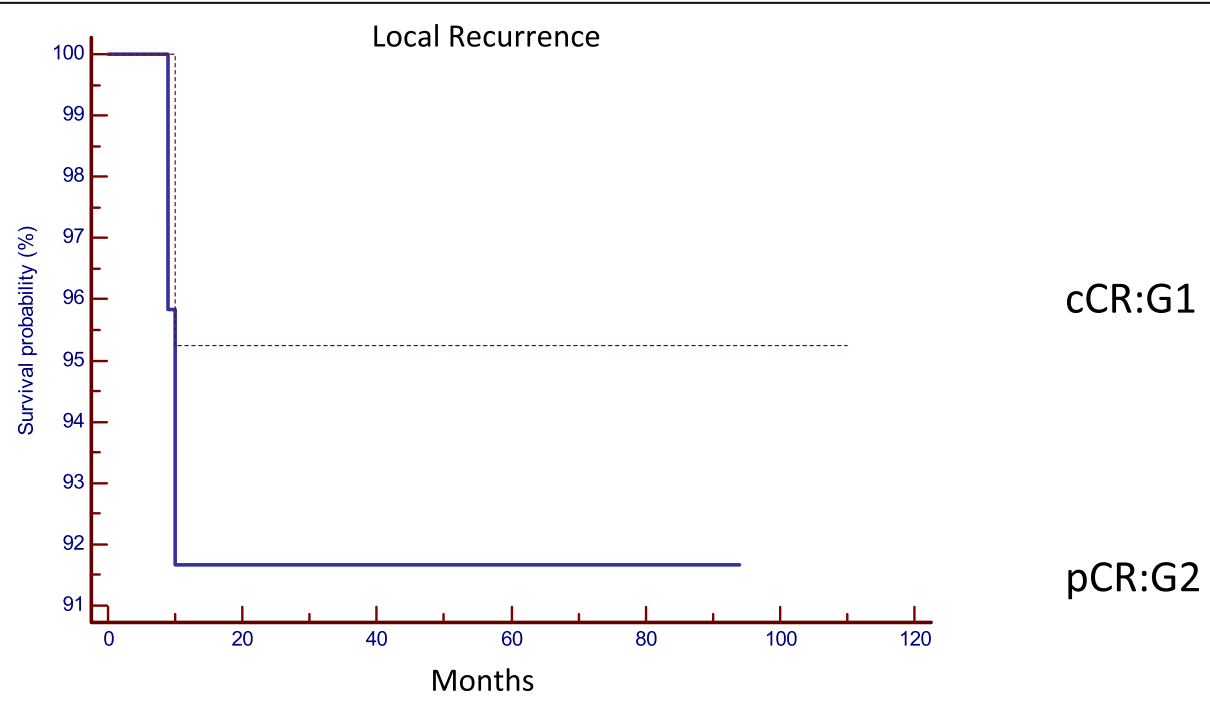

Fig. 2 Local recurrence ( $p=0.6235$, HR: 1.8004, 95\% IC 0.1867 to 17.3630). cCR clinical complete response and pCR pathological complete response 


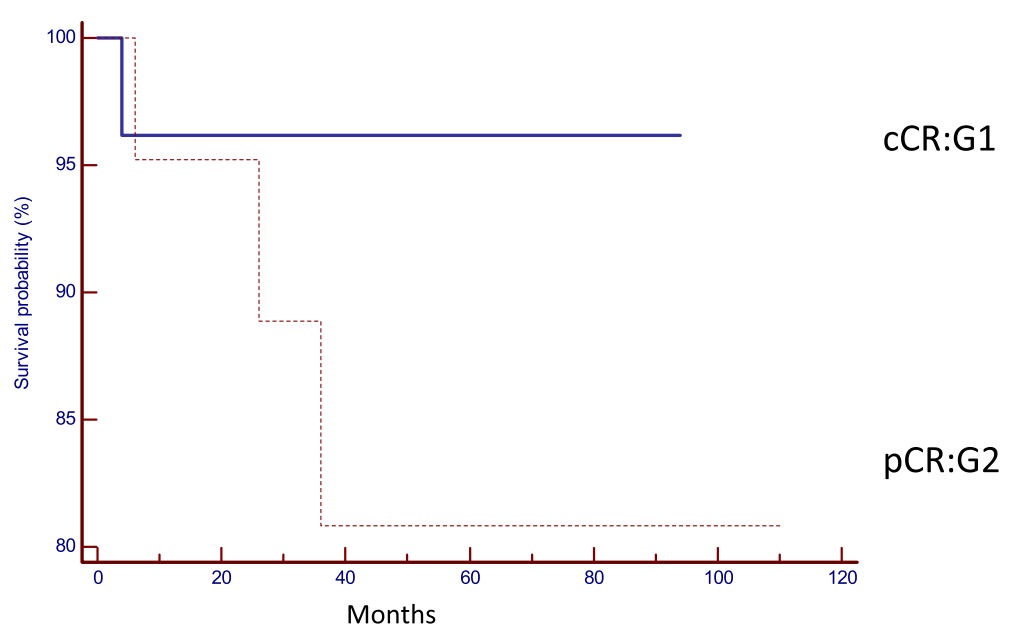

Fig. 3 Systemic recurrence ( $p=0.2237$, HR: $0.2700,95 \%$ IC 0.03763 to 1.9381). cCR clinical complete response and pCR pathological complete response

and replaced by scar tissue, and at this level of the rectal wall, only fibrosis and inflammatory processes are often found. The histopathological study of proctectomy specimens post chemoradiotherapy may confirm the absence of atypical cells in the mucosa and submucosa, both of them replaced by fibrosis and persistence of residual tumor in the periphery at a muscular layer level itself or at extramural level, concluding the histopathological staging as ypT2 or ypT3. For these reasons, in our experience, a negative endoscopic biopsy after CRTn does not at all justify to rule out the need for radical resective surgery $[28,29]$.
Conventional or minimally invasive local transanal resection (TAMIS) is an option when a minimal residual lesion or almost complete response are suspected at restaging time. This procedure was performed in three of our cases, allowing us to conduct a histopathological study of the full width of the rectal wall. This method has the limitation that any lateral spreading remained foci could be left outside the demarcated limits in the resection; the follow-up must be exhaustive when the result of the scar study was negative. In case of detecting a local recurrence, the salvage surgery can be immediately proposed $[3,6,7,22,33]$.

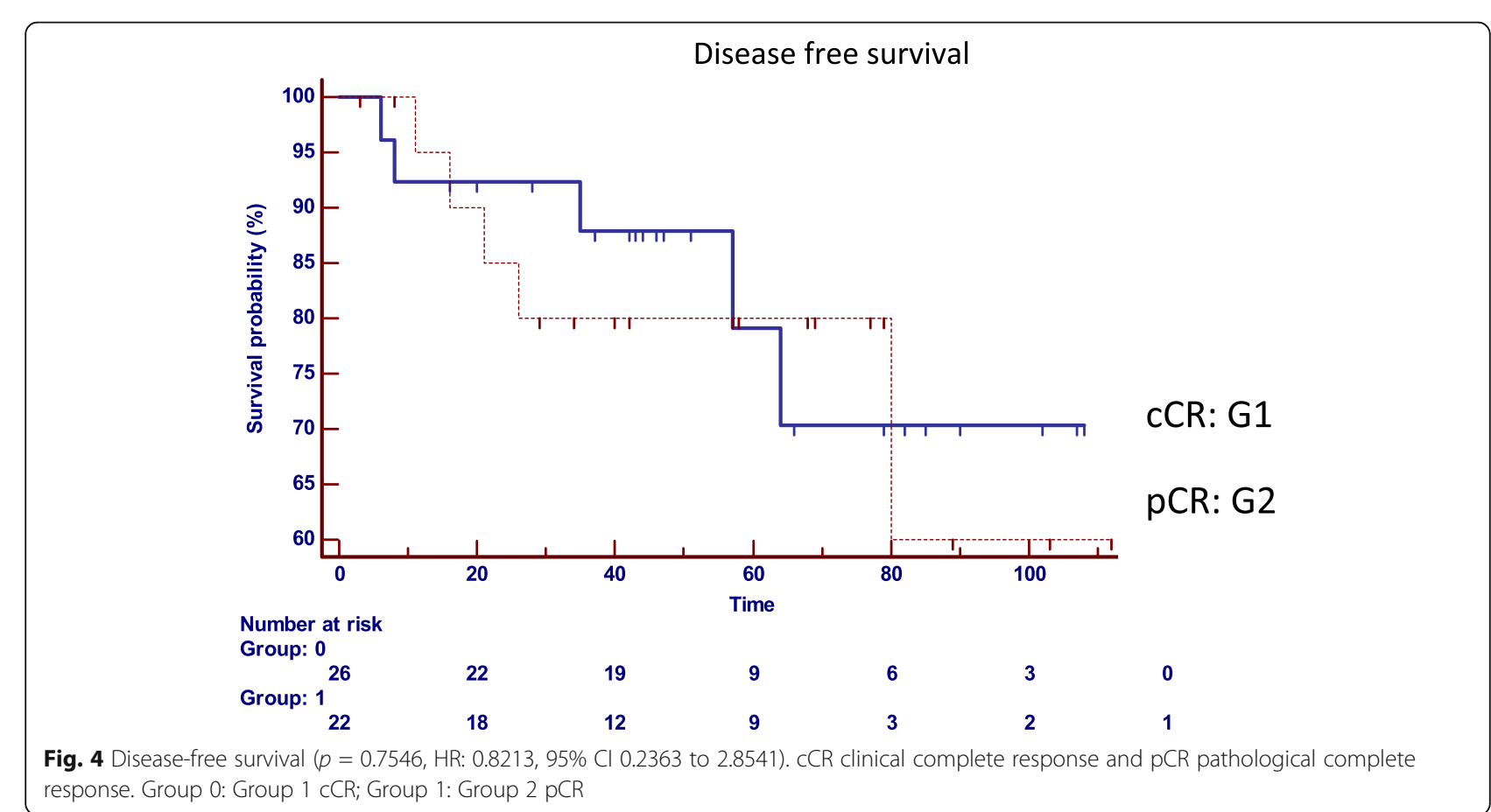



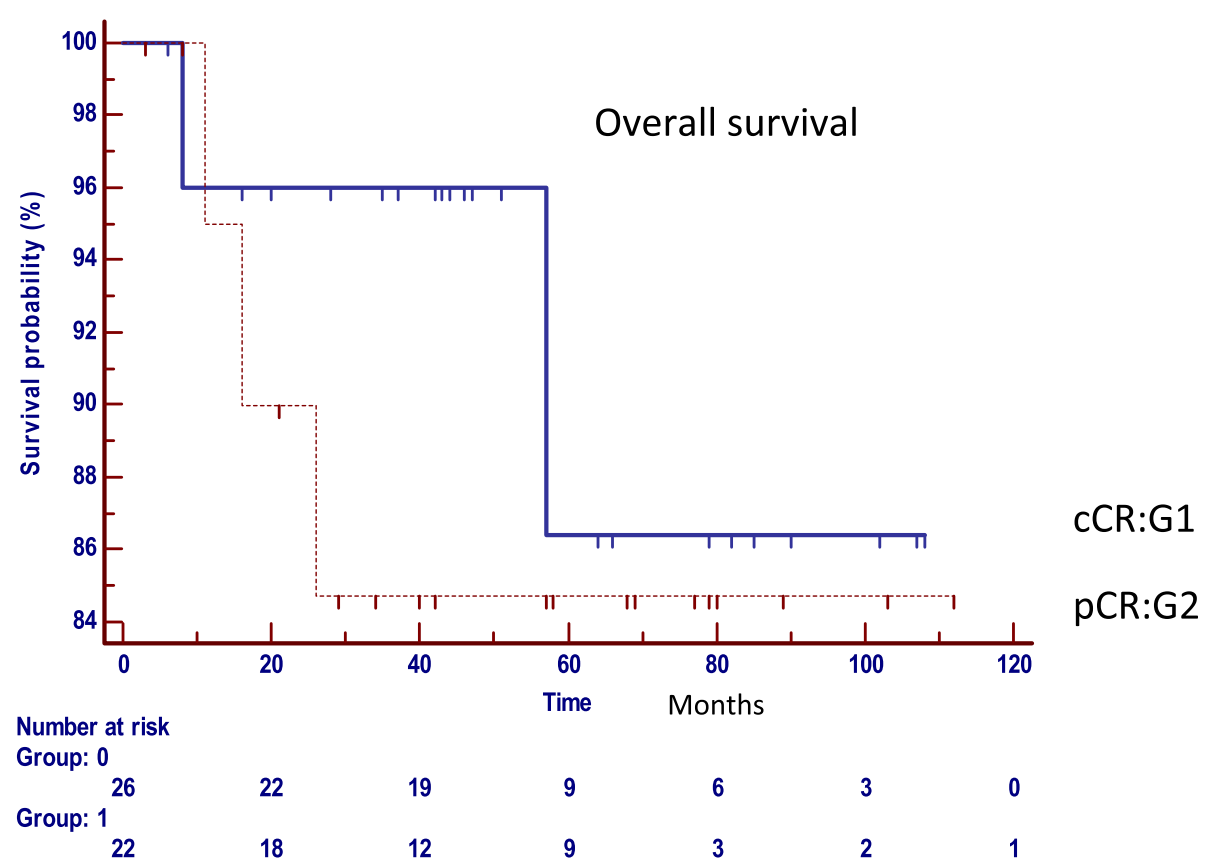

$\begin{array}{llll}9 & 6 & 3 & 0 \\ 9 & 3 & 2 & 1\end{array}$

Fig. 5 Overall survival ( $p=0.5367, \mathrm{HR}: 0.5737,95 \% \mathrm{Cl} 0.09890$ to 3.3280). cCR clinical complete response and pCR pathological complete response. Group 0: Group 1 cCR; Group 1: Group 2 pCR

Our local recurrences were detected on the luminal surface; we observed tumor regrowth in two of our patients in G1 (8.3\%), both within the first year of follow-up, coinciding with the times reported in the literature but the rates of regrowth reported were ranging from 10 to $22.1 \%$ $[6,7,22,23]$, higher than that observed in our series. Although we had a low rate of regrowth, we could not perform sphincteric preservation surgery at surgery salvage time, because of tumor location with respect to the sphincter complex. In 2018, the experience of the International Multicenter Registry, WW International Database (IWWD) was published [9], which included 880 patients with $\mathrm{CCR}$ and the local recurrence/regrowth was $25.2 \%$ (95\% CI 22.2-28.5\%), most of whom were within the first 2 years and $97 \%$ in the intestinal wall. Maybe this difference reflects the strict patient eligibility criteria for the
WW strategy of our team, the MRI systematization of response evaluation, and careful follow-up.

With regard to the distant progression of the disease, there were no statistically significant differences between the two groups, although we observed a greater tendency of distant metastases in G2 pCR. This difference is probably unrelated to the strategy implemented but related to the systemic risk characteristics of the initial staging, which are different between G1 and G2, or intrinsic molecular characteristics. The molecular predictor factors of response to CRTn are currently being studied and analyzed by our study group [34, 35].

Our results coincided with those of other groups that showed no differences between both strategies. HabrGamma et al. [26] published that in 173 patients treated with CRTn, there was $39 \%$ of cCR (67 cases), in which a

Table 3 Clinical initial staging and surgery in patients who developed systemic or local relapse

\begin{tabular}{|c|c|c|c|c|c|c|c|c|c|c|}
\hline Group & $\begin{array}{l}\text { Distance } \\
\text { from AV }\end{array}$ & $T$ & $N$ & CMR & EMVI & LPLN & $\begin{array}{l}\text { Induction } \\
C T\end{array}$ & $\begin{array}{l}\text { Adjuvant } \\
\text { CT }\end{array}$ & $\begin{array}{l}\text { Relapse } \\
\text { Surgery }\end{array}$ & Rescue \\
\hline $1 \mathrm{CCR}$ & 3 & 3 & 0 & Free & No & No & No & No & Local & APR \\
\hline $1 c C R$ & 3 & 3 & 1 & Free & No & No & No & Yes & Local & APR \\
\hline $1 c C R$ & 2 & $4 b$ & 0 & Involved & No & No & No & No & Systemic & - \\
\hline $2 \mathrm{pCR}$ & 2 & $4 b$ & 0 & Involved & No & No & No & No & Local & No \\
\hline $2 p C R$ & 10 & $3 b$ & 1 & Free & Present & Present & No & Yes & Systemic & - \\
\hline $2 p C R$ & 3 & $3 c$ & $2 a$ & Free & No & No & No & Yes & Systemic & - \\
\hline $2 p C R$ & 3 & $4 b$ & 0 & Involved & No & No & Recived & no & Systemic & - \\
\hline
\end{tabular}

$C C R$ clinical complete response, $p C R$ pathological complete response, $A V$ anal verge, $C R M$ circumferential resection margin, $E M V I$ extramural vascular invasion, $L P L N$ lateral pelvic lymph nodes, $C T$ chemotherapy, $A P R$ abdominoperineal resection 
large number of them were in initial clinical stages (I $16 \%$, II $63 \%$, and III $21 \%$ ), the local recurrence was observed in 8 patients $(11 \%)$ and distant recurrence in 7 patients $(10 \%)[4,25,26,36]$. Unlike these series, even in locally advanced tumors with higher initial risk (69\% T34 and $36 \% \mathrm{~N}+$ ), we observed that the WW strategy was safe in local and distant control and with good overall survival. Furthermore, despite this difference in initial staging, we observed good local recurrence rates of $8.3 \%$ and $3.8 \%$ of distant progression for complete clinical responders. We also noted a similar percentage for distant metastases in the international multicenter IWWD analysis, $8,1 \%$ (95\% CI $6 \cdot 2-10 \cdot 5)$, in 71 of the 880 patients included, $54 \%$ were initially staged as T3-4, and 50\% had lymph node involvement. We also coincided in the higher frequency of pulmonary rather than hepatic secondarism [9]. These observations contrast with the only series of publications of the Memorial Sloan Kettering Cancer Center (MSK) [27] in which they compared 113 cases in the WW strategy with 136 cases with pCR, showing worse overall survival at 5 years in the WW group (73\% vs. $94 \%)$, justified by a higher rate of metastatic disease in those patients who experienced regrowth of the tumor.

The overall survival in our study was 86 and $85 \%$ respectively for each group, thus confirming that our results are within the international figures mentioned above. One of the first comparative series published by Habr-Gamma et al. showed no differences between their group under observation and those of operated patients, which was $100 \%$ and $88 \%$, respectively $(p=0.01)$ [3]. Further analyses, such as this systematic review of 17 articles and 2973 cases, showed an overall survival of $93.5 \%$ [6] after 3 years of follow-up in patients under WW strategy. It is known that patients with $\mathrm{pCR}$ have better survival rates and a lower recurrence rate compared with resected patients presenting residual tumors [4].

When analyzing the impact of time until post CRTn surgery on the pCR rate, we observed that our waiting times are longer than 12 weeks due to patient-related factors, such as sociocultural and economic barriers in our public care setting, which is one of the greatest difficulties that we face, and despite this fact, we did not have higher percentages of pathological complete responders than in the different published articles on the subject (17\% of our operated post CRTn patients). The Grecca-6 trial [25] on the analysis of 265 patients from 24 medical centers, compared the percentage of pCR, by performing surgery on the 7th week or after the 11th week after CRTn and observed a percentage of 15 and $17.4 \%$ respectively without significant differences (p:NS) $[4,26]$. In contrast, Petrelli et al. [37], in a meta-analysis on 13 analyzed works and a total of 3584 patients, observed a higher percentage of $\mathrm{pCR}$ in those who underwent surgery later than 8 weeks post CRTn (19.5\%) than in those patients operated before 8 weeks (13.7\%).

Our work has limitations, such as the fact that it is a retrospective review, with a limited number of patients, WW strategy was not achieved intentionally but "accidentally," times assessment that were influenced by the characteristics of clinical practice in public health, and the impacts of its fragmentation, for example, performing radiation therapy, imaging, and chemotherapy in different medical centers. However, one of its strengths is that patients are strictly followed-up, receiving the same personal attention and systematized evaluation.

In conclusion, surgery can safely be deferred in patients with a complete clinical response; our study shows that there are no differences in local and distant recurrence and overall survival between both strategies, with similar long-term results, with the added benefit of organ preservation in the WW group, which we consider safe and with very good impact on the quality of life, always maintaining a systematized and consistent followup.

\section{Abbreviations \\ TME: Total mesorectal excision; CRTn: Neoadjuvant chemoradiotherapy; CCR: Clinical complete response; pCR: Pathological complete response; WW: Watch and wait; MRI: Magnetic resonance imaging; \\ VCC: Videocolonoscopy; EMVI: Extramural vascular invasion; \\ CEA: Carcinoembryonic antigen; CRM: Circumferential resection margin; $\mathrm{CT}$ : Computed tomography}

\section{Acknowledgements \\ Horacio Vazquez MD, for his collaboration in statistical analysis.}

\section{Authors' contributions}

MC analyzed and interpreted the patient data and acquisition of data, made substantial contributions to the conception and design, and was a major contributor in writing the manuscript. ME participated in drafting the article and revised it critically. MK participated in drafting the article and revising it critically. $\mathrm{HO}$ contributed to the acquisition of data and the design of the tables and figures. ER contributed to the writing and revised the content critically. GM contributed to the writing and revised the content critically. GM contributed to the writing and revised the content critically. II analysed and interpreted the patient data, made substantial contributions to the conception and design, and was a major contributor in writing the manuscript. All authors read and approved the final manuscript.

\section{Funding}

Not applicable

\section{Availability of data and materials}

The datasets used and analyzed during the current study are available from the corresponding author on reasonable request.

Ethics approval and consent to participate Not applicable

Consent for publication

Not applicable

Competing interests

The authors declare that they have no competing interests. 


\section{Author details}

'Colorectal Surgery Unit, Gastroenterology Hospital, Dr. Carlos Bonorino Udaondo, Av. Caseros 2061, 1264 Ciudad Autónoma de Buenos Aires (CABA), Argentina. ${ }^{2}$ Imaxe Image Diagnosis Center, Ciudad Autónoma de Buenos Aires (CABA), Argentina. ${ }^{3}$ Pathology Unit, Gastroenterology Hospital, Dr. Carlos Bonorino Udaondo, Ciudad Autónoma de Buenos Aires (CABA), Argentina. ${ }^{4}$ Coloproctology Fellowship National Health Cancer Institute, Gastroenterology Hospital, Dr. Carlos Bonorino Udaondo, Ciudad Autónoma de Buenos Aires (CABA), Argentina. ${ }^{5}$ Oncology Unit, Gastroenterology Hospital, Dr. Carlos Bonorino Udaondo, Ciudad Autónoma de Buenos Aires, Argentina.

Received: 25 August 2020 Accepted: 24 November 2020 Published online: 30 November 2020

\section{References}

1. Musio D, De Felice F, Bulzonetti N, Guarnaccia R, Caiazzo R, Bangrazi C, et al. Neoadjuvant-intensified treatment for rectal cancer: time to change? World J Gastroenterol. 2013;19(20):3052-61.

2. Sauer R, Becker H, Hohenberger W, Rödel C, Wittekind C, Fietkau R, et al. Preoperative versus postoperative chemoradiotherapy for rectal cancer. $\mathrm{N}$ Engl J Med. 2004;351:1731-40.

3. Habr-Gama A, Perez RO, Nadalin W, Sabbaga J, Ribeiro U, Silva E, et al. Operative versus nonoperative treatment for stage 0 distal rectal cancer following chemoradiation therapy: long-term results. Ann Surg. 2004; 240:711-8.

4. Smith JJ, Chow OS, Gollub MJ, Nash GM, Temple LK, Weiser MR, et al. Organ preservation in rectal adenocarcinoma: a phase II randomized controlled trial evaluating 3-year disease-free survival in patients with locally advanced rectal cancer treated with chemoradiation plus induction or consolidation chemotherapy, and total. BMC Cancer. 2015;15:1-13.

5. Habr-Gama A. Assessment and management of the complete clinical response of rectal cancer to chemoradiotherapy. Color Dis. 2006; 8(Suppl 3):21-4

6. Dattani M, Heald RJ, Goussous G, Broadhurst J, São Julião GP, HabrGama A, et al. Oncological and survival outcomes in watch and wait patients with a clinical complete response after neoadjuvant chemoradiotherapy for rectal cancer. Ann Surg. 2018;XX:1. doi: https:// doi.org/10.1097/SLA.0000000000002761.

7. Creavin B, Ryan E, Martin ST, Hanly A, O'Connell PR, Sheahan K, et al. Organ preservation with local excision or active surveillance following chemoradiotherapy for rectal cancer. Br J Cancer. 2017;116:169-74.

8. Appelt AL, Pløen J, Harling H, Jensen FS, Jensen LH, Jørgensen JCR, et al. High-dose chemoradiotherapy and watchful waiting for distal rectal cancer: a prospective observational study. Lancet Oncol. 2015;16:919-27.

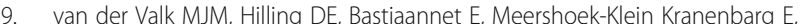
Beets GL, Figueiredo NL, et al. Long-term outcomes of clinical complete responders after neoadjuvant treatment for rectal cancer in the International Watch \& Wait Database (IWWD): an international multicentre registry study. Lancet. 2018:391:2537-45.

10. Maas M, Nelemans PJ, Valentini V, Das P, Rödel C, Kuo LJ, et al. Long-term outcome in patients with a pathological complete response after chemoradiation for rectal cancer: a pooled analysis of individual patient data. Lancet Oncol. 2010;11:835-44.

11. Nahas SC, Rizkallah Nahas CS, Sparapan Marques CF, Ribeiro U, Cotti GC, Imperiale AR, et al. Pathologic complete response in rectal cancer: can we detect it? Lessons learned from a proposed randomized trial of watch-and-wait treatment of rectal cancer. Dis Colon Rectum. 2016:59:255-63.

12. Li J, Li L, Yang L, Yuan J, Lv B, Yao Y, et al. Wait-and-see treatment strategies for rectal cancer patients with clinical complete response after neoadjuvant chemoradiotherapy: a systematic review and meta-analysis. Oncotarget. 2016;7:44857-70

13. Codina Cazador A, Farres Coll R, Olivet Pujol F, Martin Grillo A, Pujadas de Palol M, Gómez Romeu N, et al. Clinical and oncological results of the pathological complete response in rectal cancer after neoadjuvant treatment. Cirugía Española (English Ed). 2013;91:417-23.

14. Kawai K, Ishihara S, Nozawa H, Hata K, Kiyomatsu T, Morikawa T, et al. Prediction of pathological complete response using endoscopic findings and outcomes of patients who underwent watchful waiting after chemoradiotherapy for rectal cancer. Dis Colon Rectum. 2017;60:368-75.
15. Vaccaro CA, Yazyi FJ, Ojra Quintana G, Santino JP, Sardi ME, Beder D, et al. Cáncer de recto localmente avanzado: resultados preliminares de la preservación del recto después de quimiorradioterapia neoadyuvante. Cir Esp. 2016:94:274-9.

16. Habr-Gama A, Lynn PB, Jorge JMN, São Julião GP, Proscurshim I, Gama-Rodrigues J, et al. Impact of organ-preserving strategies on anorectal function in patients with distal rectal cancer following neoadjuvant chemoradiation. Dis Colon Rectum. 2016;59:264-9.

17. Smith JD, Ruby JA, Goodman KA, Saltz LB, Guillem JG, Weiser MR, et al. Nonoperative management of rectal cancer with complete clinical response after neoadjuvant therapy. Ann Surg. 2012;256:965-72.

18. Dieguez A. Resonancia magnética de alta resolución en el cáncer de recto. Rev Argent Radiol 2010;74(3)215-226. 2010:215-26

19. Washington MK, Berlin J, Branton P, Burgart LJ, Carter DK, Fitzgibbons $\mathrm{PL}$, et al. Protocol for the examination of specimens from patients with primary carcinoma of the colon and rectum. Arch Pathol Lab Med. 2009:133:1539-51.

20. Loughrey M, Quirke P, Shepherd NA. G049 dataset for histopathological reporting of colorectal cancer. R Coll Pathol. 2018:1-62.

21. Brierley JD, Gospodarowicz MK, Wittekind C. Prognosis factors for survival in differentiated colorectal cancer. In: O'Sullivan B, Maison M, Asamura H, Lee A, Van Eycken E, Denny L, Amin MB, Gupta S, editors. TNM Classification malignant tumours, Oxford, UK, 8th ed. 2017. p. 84-8.

22. Habr-Gamma A, Perez RO, Lynn PB, et al. Consideraciones sobre respuesta clínica completa en el cáncer de recto luego de quimiorradioterapia neoadyuvante. Rev Argent Coloproct. 2011;22:73-9.

23. Sanchez Loria F, Iseas S, O'Connor JM, Pairola A, Chacon M, Mendez G, et al. Non-surgical management of rectal cancer. Series of 68 cases, long follow up in two leading centres in Argentina. Dig Liver Dis. 2016;48:1372-7.

24. Glynne-Jones R, Wyrwicz L, Tiret E, Brown G, Rödel C, Cervantes A, et al. Rectal cancer: ESMO clinical practice guidelines for diagnosis, treatment and follow-up. Ann Oncol. 2017;28:iv22-40.

25. Lefevre JH, Mineur L, Kotti S, Rullier E, Rouanet P, De Chaisemartin C, et al. Effect of interval (7 or 11 weeks) between neoadjuvant radiochemotherapy and surgery on complete pathologic response in rectal cancer: a multicenter, randomized, controlled trial (GRECCAR-6). J Clin Oncol. 2016;34:3773-80.

26. Habr-Gama A, Perez RO, São Julião GP, Proscurshim I, Gama-Rodrigues J. Nonoperative approaches to rectal cancer: a critical evaluation. Semin Radiat Oncol. 2011;21:234-9.

27. Smith JJ, Strombom P, Chow OS, Roxburgh CS, Lynn P, Eaton A, et al. Assessment of a watch-and-wait strategy for rectal cancer in patients with a complete response after neoadjuvant therapy. JAMA Oncol. 2019;5.

28. Perez RO, Habr-Gama A, Pereira GV, Lynn PB, Alves PA, Proscurshim I, et al. Role of biopsies in patients with residual rectal cancer following neoadjuvant chemoradiation after downsizing: can they rule out persisting cancer? Color Dis. 2012:14:714-20.

29. Nagtegaal ID, Glynne-Jones R. How to measure tumour response in rectal cancer? An explanation of discrepancies and suggestions for improvement. Cancer Treat Rev. 2020;84:101964

30. Iseas IS, Carballido M, Coraglio M, Leiro F, Dieguez A, Eleta M, et al. Moving foward and beyond the standard through a non-operative management in rectal cancer? Our watch and wait approach experience in co-recto. J Clin Oncol. 2015;33:3561.

31. Iseas S, Carballido M, Coraglio M, Leiro F, Dieguez A, Eleta M, et al. Still awaiting that waiting be a validated affordable option in rectal cancer? Our watch and wait approach experience in co-recto. Ann Oncol. 2014:25:ii99.

32. Iseas $S$, Coraglio M, Dieguez A, Eleta M, Bertoncini C, Tejerina H, et al. P-127 pathological versus clinical complete responders after preoperative treatment in rectal cancer: long term outcomes analysis. Ann Oncol. 2016;27:ii37.

33. Perez RO, Habr-Gama A, Smith FM, Kosinski L, São Julião GP, Grzona E, et al. Fragmented pattern of tumor regression and lateral intramural spread may influence margin appropriateness after TEM for rectal cancer following neoadjuvant CRT. J Surg Oncol. 2014;109:853-8.

34. Sendoya JM, Iseas S, Golubicki M, Robbio J, Coraglio MF, Gualdrini U, et al. Abstract LB-374: transcriptome-based inference of immune cell subsets and pathway deregulation in rectal cancer reveals biological processes related to therapy response. Cancer Res. 2018;78:LB-374 LP-LB-374.

35. Iseas S, Sendoya Juan M, Golubicki M, Coraglio M, Gualdrini U, Cabanne A, et al. Comprehensive clinical, pathological and molecular 
characterization of a cohort of locally advanced rectal cancer patients: towards an integrative classification for rectal cancer management. Ann Oncol. 2017;28:iii125-6.

36. Habr-Gama A, São Julião GP, Vailati BB, Fernandez LM, Ortega CD,

Figueiredo $\mathrm{N}$, et al. Organ preservation among patients with clinically nodepositive rectal cancer: is it really more dangerous? Dis Colon Rectum. 2019; 62:675-83.

37. Petrelli F, Sgroi G, Sarti E, Barni S. Increasing the interval between neoadjuvant chemoradiotherapy and surgery in rectal cancer: a metaanalysis of published studies. Ann Surg. 2016;263:458-64.

\section{Publisher's Note}

Springer Nature remains neutral with regard to jurisdictional claims in published maps and institutional affiliations.

Ready to submit your research? Choose BMC and benefit from:

- fast, convenient online submission

- thorough peer review by experienced researchers in your field

- rapid publication on acceptance

- support for research data, including large and complex data types

- gold Open Access which fosters wider collaboration and increased citations

- maximum visibility for your research: over $100 \mathrm{M}$ website views per year

At BMC, research is always in progress.

Learn more biomedcentral.com/submissions 